\title{
PAGE4 promotes prostate cancer cells survive under oxidative stress through modulating MAPK/JNK/ERK pathway
}

\author{
Chengcheng $\mathrm{Lv}^{1 \dagger}$, Shui Fu ${ }^{1 \dagger}$, Qingzhuo Dong ${ }^{2}$, Zi Yu², Gejun Zhang ${ }^{2}$, Chuize Kong ${ }^{2}$, Cheng Fu ${ }^{1}$ and Yu Zeng ${ }^{1 *}$
}

\begin{abstract}
Background: Prostate cancer (PCa) is one of the most common cancers in male worldwide. Oxidative stress has been recognized as one of the driving signals pathologically linked to PCa progression. Nevertheless, the association of oxidative stress with PCa progression remains unclear.
\end{abstract}

Methods: Western blot, q-RT-PCR and bioinformatics analyses were used to examine PAGE4 expression. Comet assay and Annexin V/ PI dual staining assay were performed to investigate DNA damage and cell death under oxidative stress. Mouse xenograft model of PCa cells was established to verify the role of PAGE4 in vivo. Transcriptomic analysis was performed to investigate the underlying mechanism for the function of PAGE4 under oxidative stress. Western blot assay was conducted to determine the status of MAPK pathway. Immunohistochemistry was used to identify protein expression of PAGE4 in tumor tissues.

Results: In this study, we found that PAGE4 expression was increased in PCa cells under oxidative stress condition. PAGE4 overexpression protected PCa cells from oxidative stress-inducing cell death by reducing DNA damage. PAGE4 overexpression promoted PCa cells growth in vivo. Mechanistically, PAGE4 promoted the survival of prostate cancer cells through regulating MAPK pathway which reflected in decreasing the phosphorylation of MAP2K4, JNK and c-JUN but increasing phosphorylation of ERK1/2.

Conclusion: Our findings indicate that PAGE4 protects PCa cells from DNA damage and apoptosis under oxidative stress by modulating MAPK signalling pathway. PAGE4 expression may serve as a prognostic biomarker for clinical applications.

Keywords: PAGE4, Oxidative stress, Prostate Cancer, MAPK, ERK

\section{Background}

Prostate cancer $(\mathrm{PCa})$ remains the third killer in men with all kinds of cancers [1]. Although the 5-year survival rate for most men with local or regional prostate cancer is almost $100 \%$, for those patients with tumors spreading to other parts of the body, the 5-year survival rate is merely $29 \%$ [1]. Basically, androgen deprivation therapy can delay the progression of cancer; however, many patients would end up with castration resistant prostate cancer (CRPC), which is currently incurable [2].

\footnotetext{
*Correspondence: zengyud@hotmail.com

${ }^{\dagger}$ Chengcheng Lv and Shui Fu contributed equally to this work.

'Department of Urology, Cancer Hospital of China Medical University,

Liaoning Cancer Hospital and Institute, 44 Xiaoheyan Road, Shenyang

110042, Liaoning, China

Full list of author information is available at the end of the article
}

PAGE4 (Prostate Associate Gene 4) belongs to the Cancer Testis Antigen (CTA) family, which are normally expressed only in adult testis but not in other mature tissues. However, in many tumors or other diseases, the CTA genes are re-expressed again [3, 4]. Accumulating evidence from varied studies including those from our group has shown that PAGE4 is re-expressed in human diseased prostate, particularly in the stroma of symptomatic benign prostatic hyperplasia (BPH) [5], and in the epithelia of proliferative inflammatory atrophy (PIA) that is considered as a precursor of $\mathrm{PCa}$, as well as in PCa itself [6-11]. Interestingly, the expression of PAGE4 was found to be significantly lower in androgen-resistant prostate cancer than primary prostate cancer [8]. Additionally, PAGE4 was recently found to be related to

(C) The Author(s). 2019 Open Access This article is distributed under the terms of the Creative Commons Attribution 4.0 International License (http://creativecommons.org/licenses/by/4.0/), which permits unrestricted use, distribution, and 
androgen receptor function, while different phosphorylated format catalyzed by two kinases contributed to PAGE4 conformational dynamics and androgen-dependence switching in PCa $[12,13]$. We previously screened prognostic indicators of prostate cancer using tissue samples, and found that the transcription level of PAGE4 in prostate cancer tissues was negatively correlated with the biological recurrence of cancer [14]. At the same time, another study indicated that the expression level of PAGE4 varied in prostate cancer tissues with different Gleason scores [15], suggesting that it might be used as an auxiliary indicator of prostate cancer malignancy. Thus, the involvement of PAGE4 in diseased prostate, particularly in the prostate cancer, is somehow founded. However, the exact functional role of PAGE4 in the context of signalling pathways under a diseased status of prostate cancer remains largely unclear.

Our previous study has found that PAGE4 is an intrinsic disorder protein (IDP) and can protect cells from stress $[16,17]$. Further studies have shown that the regulatory mechanism of PAGE4 may be related to the phosphorylation of the Thr-51 amino acid site stimulated by the homeodomain-interacting protein kinase 1 (HIPK1) $[18,19]$ and of multiple $\mathrm{S} / \mathrm{T}$ residues catalyzed by CDC-Like Kinase 2 (CLK2) [13]. In cellular process, we previously showed that PAGE4 mainly localized in mitochondria, and overexpressing PAGE4 protected cancer cells from different kinds of stress such as glucose deprivation, treatment of TNF $\alpha$ or chemical drug, through increasing the protein level of p21 [10]. However, when cells were exposed to $\mathrm{H}_{2} \mathrm{O}_{2}$, p21 level was not changed, suggesting that PAGE4 may protect cells from oxidative stress in a different manner. One possible explanation of this phenomenon is that PAGE4 interacts with c-JUN and then activates MAP kinase signalling pathway [20], but the detail mechanism still needs to be further studied.

Here, we focused on the PAGE4 regulation on oxidative stress in PCa cells. We found that treatment of $\mathrm{H}_{2} \mathrm{O}_{2}$ significantly increased the expression of PAGE4, which exactly protected cells from apoptosis under the stress status. In addition, PAGE4 overexpression promoted tumor growth in xenograft mouse models. Further RNA-sequencing study revealed a potential involvement of Mitogen-activated protein kinase (MAPK) pathway in PAGE4 regulation on oxidative stress. Thus, the present results may expand our understanding of the role of PAGE4 on stress response to reactive oxygen species (ROS) which is critical to the development of PCa.

\section{Methods}

\section{Cell culture}

All cell lines were obtained from the Cell Bank of the Shanghai Institutes of Biological Sciences, Chinese Academy of Sciences. Human prostate cancer cell lines 22RV1,
DU145, PC3 and LNCaP were cultured in RPMI-1640 (Gibco, China), $293 \mathrm{~T}$ cells were cultured in DMEM (Gibco, China), and both media contained $10 \%$ fetal bovine serum (Gemini, USA) and 1\% penicillin-streptomycin (Gibco, USA). All cell lines were cultured at $37^{\circ} \mathrm{C}$ in a humidified atmosphere of $5 \% \mathrm{CO}_{2}$.

\section{Construction and production of lentiviral vector}

Open reading frame of PAGE4 with HA N-terminal tag was cloned into pLVX-TetOne-Puro (Clontech, USA) vector using In-Fusion HD method following the protocol provided by Clontech. Briefly, vector was digested by EcoR I (New England Biolabs, USA) and BamH I for linearization, then mixed with insert DNAs in In-Fusion cloning reaction buffer. Alternatively, open reading frame of CLK2 or HIPK1 with 3X Flag N-terminal tag were amplified from human cDNA library, and then digested by BamH I and Xba I for CLK2, and Xho I and Not I for HIPK1. The insert DNAs were cloned into pLVX-Puro (Clontech) vector. After construction, vectors were transduced into E. coli. Screened clones were expanded, and plasmids were extracted and purified. Then the over-expressing vectors or empty vectors were co-transfected with 2nd Generation Packaging System Mix (Abmgood, Canada) into $293 \mathrm{~T}$ cells using calcium phosphate transfection method [21]. After culturing transfected $293 \mathrm{~T}$ cells in DMEM media for $48 \mathrm{~h}$, the supernatant containing lentivirus were harvested and filtered with a $0.45 \mu \mathrm{m}$ filter (Merck Millipore, Germany).

\section{Cell transfection}

Lentivirus were added into target cell lines with $8 \mu \mathrm{g} / \mathrm{mL}$ polybrene (Sigma-Aldrich, USA), then cells were centrifuged for $1 \mathrm{~h}$ at $500 \mathrm{rpm}$ to aid transfection. After $72 \mathrm{~h}$, cells were treated with $2 \mu \mathrm{g} / \mathrm{mL}$ of puromycin (Invivogen, USA) for 2 weeks, and survival cells were maintained in medium supplemented with $200 \mathrm{ng} / \mathrm{mL}$ of puromycin.

\section{Cell treatment}

To enable the expression of transduced gene, $1 \mathrm{mg} / \mathrm{L}$ of doxycycline (DOX, Clontech) was added into all transfected cells for at least $48 \mathrm{~h}$ before analysis. To stimulate ROS in vitro, $200 \mathrm{mM} \mathrm{H}_{2} \mathrm{O}_{2}$ was added to cells for $12 \mathrm{~h}$ before analysis unless otherwise stated. $5 \mathrm{mMN}$-Acetyl-L-cysteine (NAC, Sigma-Aldrich) was given to cells for $12 \mathrm{~h}$ before collection.

\section{RNA extraction and real-time quantitative PCR}

Total RNA was extracted using TRIzol reagent (Invitrogen, USA) according to the manufacturer's instructions. cDNA was synthesized using PrimeScript ${ }^{\mathrm{tm}}$ RT Master Mix (Takara, Japan), and quantitative real-time PCR was performed using SYBR Premix EX Taq ${ }^{\text {Tim }}$ II (Takara). $\mathrm{ACTB}$ was used as a reference gene. The primer 
sequences used to amplify the target genes are searched from PrimerBank $[22,23]$. The sequence of primers are listed in Additional file 1: Table S1. The real-time PCR was performed as follows: $3 \mu \mathrm{L}$ of $\mathrm{ddH}_{2} \mathrm{O}, 5 \mu \mathrm{L}$ of $2 \times$ SYBR mix, $0.5 \mu \mathrm{L}$ of forward primer, $0.5 \mu \mathrm{L}$ of reverse primer and $1 \mu \mathrm{L}$ cDNA templates were mixed together. The PCR reaction consisted of an initial denaturation at $95^{\circ} \mathrm{C}$ for $30 \mathrm{~s}$, followed by 40 cycles of denaturation at $95^{\circ} \mathrm{C}$ for $5 \mathrm{~s}$, annealing at $60^{\circ} \mathrm{C}$ for $30 \mathrm{~s}$. The $\triangle \mathrm{CT}$ method was performed to calculate the relative expression [24].

\section{ROS assay}

ROS activity was measured with $2^{\prime}, 7^{\prime}$-dichlorofluorescin diacetate (DCFDA, Sigma). Cells were seeded at 25,000 cells per wells in 96 well plates the day before assay. When experiment, cells were washed with PBS once, then stained with $20 \mu \mathrm{M}$ of DCFDA for $30 \mathrm{~min}$ for LNCaP cells, and $25 \mu \mathrm{M}$ of DCFDA for $45 \mathrm{~min}$ for DU145 cells, respectively. After washed with PBS, cells were treated with $2 \mathrm{mM}$ of $\mathrm{H}_{2} \mathrm{O}_{2}$ or PBS in DMEM medium without supplemental phenol red for one hour, then were measured under microplate reader (BioTek Instruments, USA). Unstained cells from each group were used for standardization.

\section{Western blotting}

Cells were harvested in RIPA lysis buffer (Beyotime, China), then the protein concentrations were measured using the BCA protein assay kit (Invitrogen, USA). After that, protein was heated for $5 \mathrm{~min}$ at $99^{\circ}$ $\mathrm{C}$, and $20 \mu \mathrm{g}$ of protein were loaded into each lane and separated by $10 \%$ SDS-PAGE in Tris-glycine running buffer, and then transferred to PVDF membranes (Millipore). The membranes were blocked with 5\% skimmed milk in TBST at room temperature for $1 \mathrm{~h}$ and then incubated with primary antibodies at $4{ }^{\circ} \mathrm{C}$ overnight. After three washes with TBST for $5 \mathrm{~min}$ each, the membranes were incubated with 1:3000 HRP-coupled secondary antibody (Abmgood, Canada) in 5\% skimmed milk in TBST for $1 \mathrm{~h}$. The membranes were then washed for three more times with TBST and visualized using the Pierce ECL Plus (Thermofisher, USA). Antibodies against PAGE4 (Sigma-Aldrich, USA) was diluted in 5\% skimmed milk in TBST at 1:500, and antibody against $\beta$-actin (Sigma-Aldrich) was diluted in $5 \%$ skimmed milk in TBST at 1:5000, while antibodies against pMAP2K4, pJNK, JNK, pATF2, p-c-JUN, pERK, ERK (Cell Signaling Technology, USA) were all diluted in $5 \%$ bovine serum albumin (Sangon, China) in TBST at 1:1000. Integral optical density (IOD) of each band was measured by using Gel-Pro Analyzer (version 4.0, Media Cybernetics, USA).

\section{Comet assay}

The alkaline comet assay was performed using CometAssay Reagent kit for Single Cell Gel Electrophoresis Assay (Trevigen, USA) according to the manufacturer's protocol. Briefly, cells were collected then suspended at $1 \times 10^{5}$ cells per $\mathrm{mL}$, and $20 \mu \mathrm{L}$ cell suspension combined with $200 \mu \mathrm{L}$ LMAgarose with final volume of $50 \mu \mathrm{L}$ were then pipetted onto each CometSlide. When a clear ring appeared, the slides were incubated in Lysis Solution for $30 \mathrm{~min}$. Then the slides were sunk in alkaline unwinding solution for $20 \mathrm{~min}$ at room temperature. Slides were electrophoresed in alkaline electrophoresis solution at $21 \mathrm{~V}, 300 \mathrm{~mA}$ for $30 \mathrm{~min}$ at $4{ }^{\circ} \mathrm{C}$. The slides were drained and stained with $1 \times$ SYBR Gold (ThermoFisher). Cell images were captured using an Olympus AX70 fluorescence microscope (Olympus, Japan) and single cells tail length, tail DNA percentage were measured by CometScore version 2.0 (TriTek, USA) software [25].

\section{Annexin V/ Propidium iodide (PI) double-staining assay}

Annexin V-FITC apoptosis detection kit (BD biosciences, USA) was used to analyse the apoptosis. Annexin $\mathrm{V}$ and propidium iodide staining was performed according to the manufacturer's protocol. Briefly, $10^{4}$ cells in $100 \mu \mathrm{L} 1 \times$ Binding Buffer were stained with $5 \mu \mathrm{L}$ FITC Annexin $\mathrm{V}$ and $5 \mu \mathrm{L}$ PI for $15 \mathrm{~min}$ at room temperature. Stained cells were detected using a FACScan flow cytometer (BD biosciences) and data was collected using FlowJo version 10.0.7 (FlowJo, USA) software. FITC positive cells whether or not with PI positive staining were calculated as apoptotic cells.

\section{Xenograft tumor model}

Twelve severe combined immunodeficiency (SCID) mice with 7 weeks old were randomly divided into three groups, 4 in each. DU145 cells $\left(2.5 \times 10^{6}\right)$ that were stably transfected with conditional PAGE4-overexpressing vector or empty vector were mixed with matrigel (Coring, USA) at a ratio of 1:1, and then injected subcutaneously in both flanks of mice in each group under isoflurane anaesthesia [26]. DOX was added in drinking water at $500 \mathrm{mg} / \mathrm{L}$ with $3 \%$ sucrose to all mice [27]. Normal saline or $200 \mathrm{mg} / \mathrm{kg} \mathrm{NAC}$ was intraperitoneal injected daily from day14 [28]. At day 28, the animals were sacrificed and the tumors were removed, weighed and homogenized to extract RNA.

\section{RNA-sequencing and analysis}

RNA was extracted from different cell lines using RNeasy Plus Universal Kits (QIAGEN, Germany) according to the manufacturer's instructions. RNA library construction and sequencing was performed by Berry Genomics (Beijing). Raw RNA sequences data were then 
mapped to the GRCh38 (hg38) genome using HISAT2 2.1.0 [29]. FeatureCounts 1.6.0 [30] was used to count reads and generate raw counts for per gene. Differential analysis of count data was carried out by DESeq2 3.7 [31]. Differentially expressed genes (DEGs) were then identified using fold change of the target group to the control group ratios $>1.5$. Gene Set Enrichment Analysis (GSEA) [32] was performed by using publicly available software downloaded from the Broad Institute [33]. Main parameters setting of GSEA were weighted enrichment statistic and Diff_of_Classes metric for ranking genes. Protein-protein interaction (PPI) was analysed through String [34]. Sequencing data have been deposited in Gene Expression Omnibus (GEO) with accession number GSE119005.

\section{Dataset analysis}

The TCGA-PRAD data was downloaded from the TCGA portal [35]. This dataset includes the RNA sequencing data of 498 tumor tissue samples, generated using Ilumina sequencing technology. And $\mathrm{R}$ packages for Survival Analysis [36] was used to perform disease-free survival analysis. 109 samples were defined as PAGE4 high expression and 84 samples were low expression.

\section{Immunohistochemistry}

Expression of PAGE4 and pERK1/2 was assessed by immunohistochemistry using paraffin-embedded tissue sections obtained from the department of pathology in Cancer Hospital of China Medical University. Briefly, the sections were deparaffinised and then boiled in citrate unmasking solution for $35 \mathrm{~min}$. After incubated in $3 \%$ hydrogen peroxide for $10 \mathrm{~min}$, sections were blocked with $5 \%$ BSA for $1 \mathrm{~h}$ at room temperature, and then incubated with rabbit anti-human PAGE4 (1:200, Abcam, USA) or rabbit anti-human pERK1/2 (1:400, CST, USA) antibodies overnight at $4{ }^{\circ} \mathrm{C}$. After that, sections were incubated with appropriate secondary antibodies (Zsbio, China) and then stained with DAB \& Hematoxylin.

\section{Statistical analysis}

All in vitro experiments were repeated at least three times. Data was shown as mean \pm SEM, and statistical analyses were carried out using SPSS 22.0 (IBM, USA) or Graphpad Prism 7 (Graphpad, USA). The Student's $t$-test was used to evaluate the significance of differences for Comet assay, Annexin V/ Propidium Iodide (PI) double-staining assay and ROS assay. Mann-Whitney U test was used to evaluate the significance of differences for q-RT-PCR, Western blot and tumor weight. For survival analysis, the Kaplan-Meier method was used to estimate the survival curves, and the log-rank test for the comparison. A $p$-value $<0.05$ was considered significant.

\section{Results}

Expression level of PAGE4 was increased under ROS stimulation in prostate cancer cell lines

ROS can induce DNA damage and increase the risk of DNA mutation that may lead to activation of oncogene and development of cancer [37, 38]. Knowing how ROS acts in prostate cancer can help us find ways to fight against cancer. To test, we used $\mathrm{H}_{2} \mathrm{O}_{2}$ to simulate ROS in prostate cancer cell lines 22RV1, DU145, PC3, and LNCaP, which cover both androgen-sensitive and -insensitive cell lines. As shown in Fig. 1 a, ROS related gene SOD1 was increased after $\mathrm{H}_{2} \mathrm{O}_{2}$ treatment in all the cell lines, suggesting that prostate cancer cells were indeed experienced a high level of oxidative stress no matter a subtype of PCa cells. In addition, endogenous ROS assay also showed that cells tolerated a high oxidative stress after hydrogen peroxide treatment (Additional file 2: Figure S1). At the same time, NAC that is a penetrating antioxidant significantly reduced the oxidative stress caused by $\mathrm{H}_{2} \mathrm{O}_{2}$ in cells, indicated by reducing the transcriptional level of SOD1 (Fig. 1 a). On the other hand, the mRNA level of PAGE4 was increased in all of these lines after $\mathrm{H}_{2} \mathrm{O}_{2}$ treatment (Fig. 1 b), while NAC treatment effectively inhibited the effect of $\mathrm{H}_{2} \mathrm{O}_{2}$ on PAGE4 expression. Moreover, the upregulation of PAGE4 under $\mathrm{H}_{2} \mathrm{O}_{2}$ treatment showed a typical manner of time-dependent and dose-dependent (Fig. 1 c, d). Accordingly, in 22RV1 cells, the expression of PAGE4 was greatly increased when cells were treated with $\mathrm{H}_{2} \mathrm{O}_{2}$ from $0 \mathrm{~h}$ to $8 \mathrm{~h}$. Similarly, more $\mathrm{H}_{2} \mathrm{O}_{2}$ was added, higher levels of PAGE4 mRNA were detected. These results suggest that the mRNA expression of PAGE4 be induced by ROS stress.

\section{Prostate cancer cells with PAGE4 overexpression tolerate oxidative stress}

We have previously shown that silencing PAGE4 expression inhibits cell survival and enhances chemo-cytotoxicity in prostate cancer cells [16]. In such circumstance, PAGE4 may protect cancer cells through upregulation of p21 in most stress status with exception of $\mathrm{H}_{2} \mathrm{O}_{2}$, in which p21 level was not altered in either PAGE4-expressing cells or PAGE4-knocking down cells [10]. To investigate how PAGE4 is involved in oxidative stress protection in prostate cancer, we established inducible PAGE4-overexpressing cell lines, in which both mRNA and protein levels of PAGE4 were significantly increased by treatment of DOX (Fig. 2 a, b). As shown in Fig. 2 b, c, d, the expression of PAGE4 were induced by $\mathrm{H}_{2} \mathrm{O}_{2}$ both in empty vector and PAGE4 construct-transfected cells, even though the basic mRNA level of PAGE4 was much higher in PAGE4 construct-transfected cells than empty vector-transfected cells. The fact that both endogenous and exogenous PAGE4 gene can be induced 


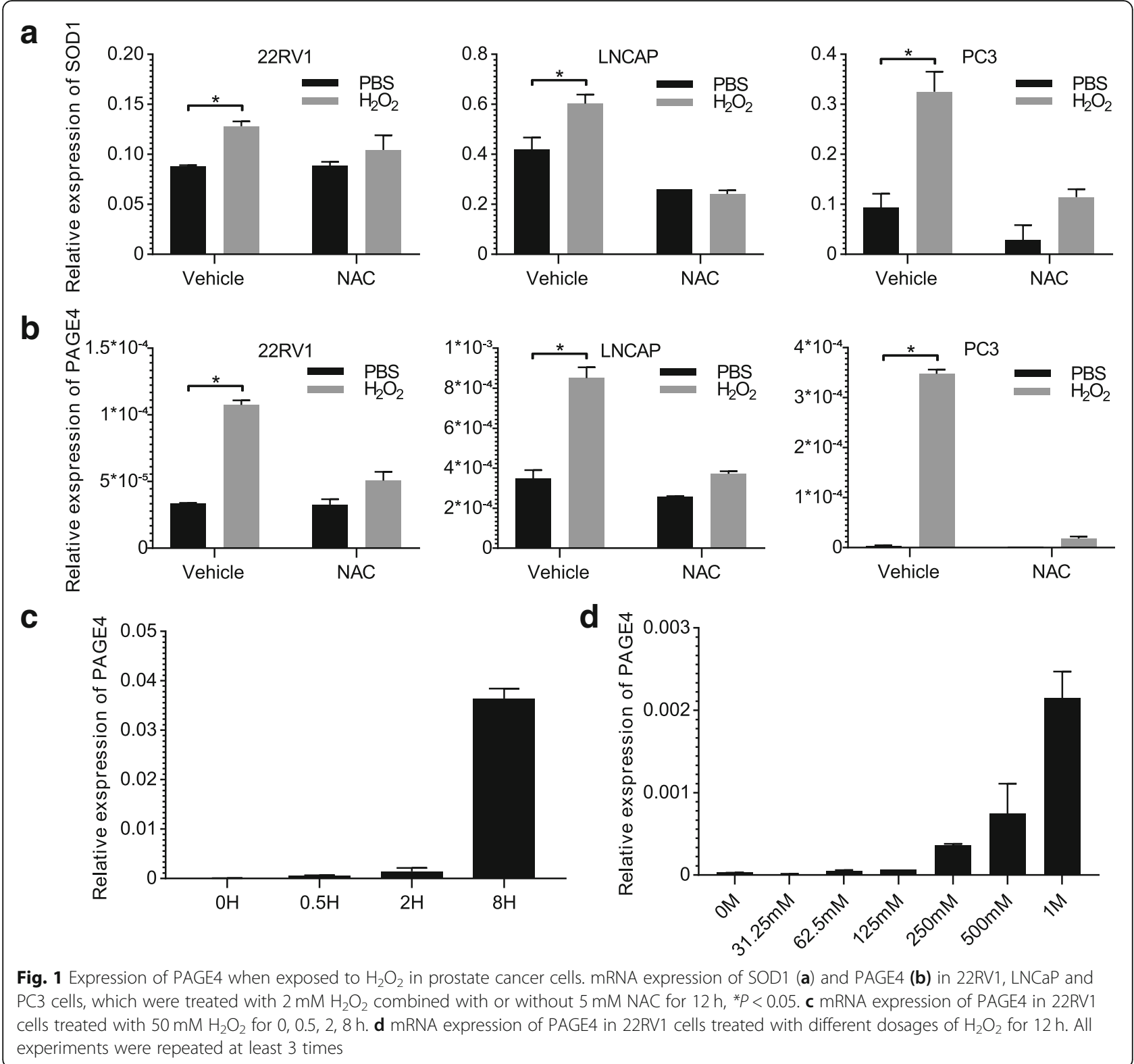

by ROS suggests that the regulation of PAGE4 by ROS may be related to a post-transcriptional way.

Previous studies demonstrated that CLK2 and HIPK1 both phosphorylate PAGE4 and therefore differently regulate its activity $[13,39]$. We ask whether the specific phosphorylation state of PAGE4 impact its regulation in ROS response. To test, CLK2 or HIPK1 were co-transfected with PAGE4 into DU145 or LNCaP cells and treated with $\mathrm{H}_{2} \mathrm{O}_{2}$. Then, the intracellular levels of ROS were measured to evaluate the oxidative stress status. As shown in Fig. 2e, while PAGE4 overexpression alone reduced ROS production in both cell lines, co-transfecting PAGE4 with CLK2 did not impact ROS level compared to control cells.
This result suggests that CLK2 inhibit PAGE4 activity in suppressing ROS production under ROS stress. However, when PAGE4 was co-tranfected with HIPK1, the intracellular ROS was changed differently in these two cell lines. Namely, in LNCaP cells, co-expression of HIPK1 with PAGE4 reduced ROS production even less than what caused by overexpression of PAGE4 alone after $\mathrm{H}_{2} \mathrm{O}_{2}$ treatment. By contrast, in DU145 cells, co-transfection of HIPK1 and PAGE4 increased but not decreased ROS level as compared to control cells. These findings suggest that HIPK1 may impact PAGE4 function during ROS response in a cell type-dependent manner, although further study is clearly needed. 
a

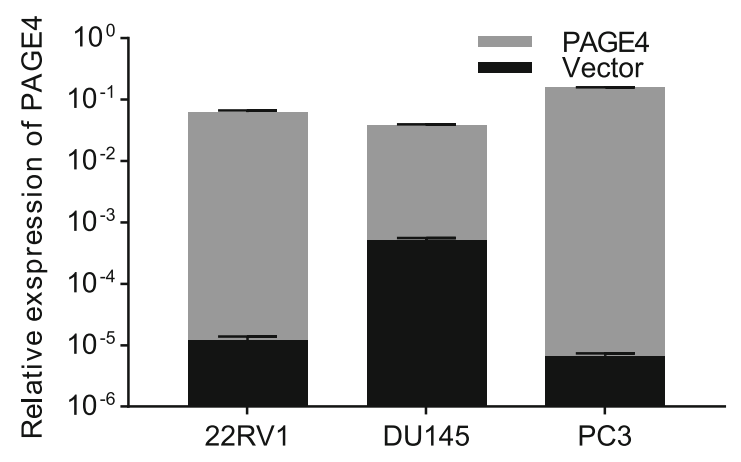

C

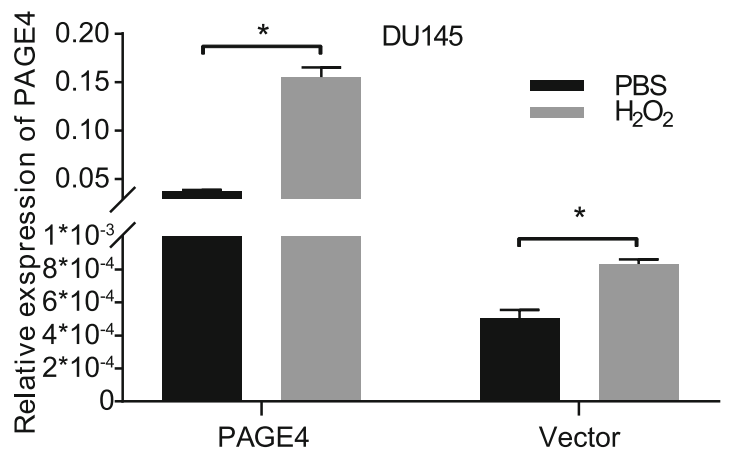

b

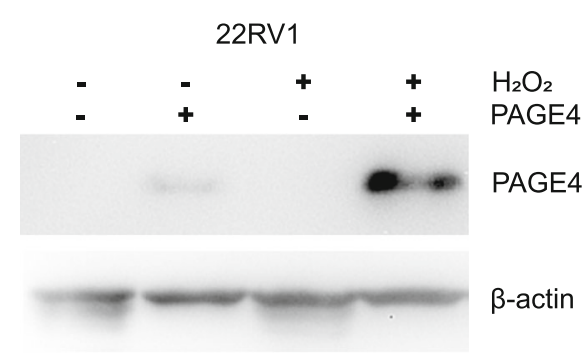

d

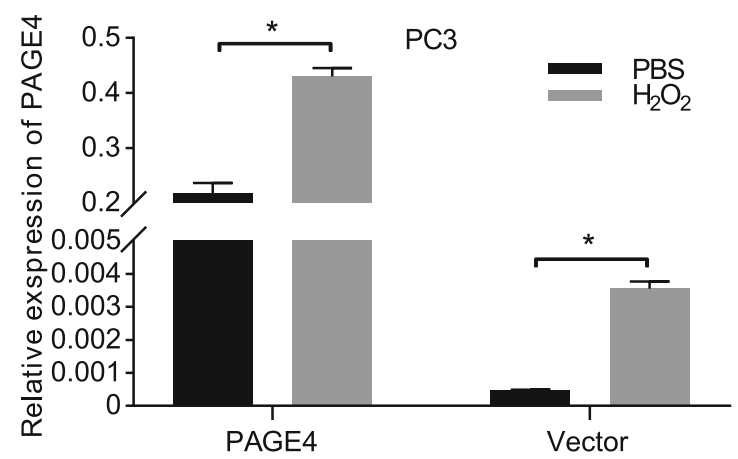

e

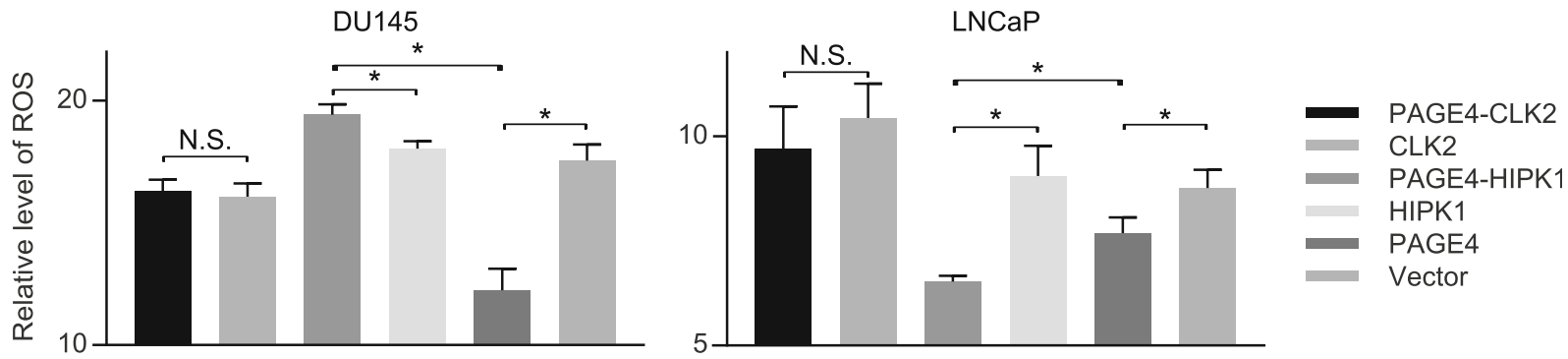

Fig. 2 Overexpression of PAGE4 in PCa cells. a mRNA expression of PAGE4 in 22RV1, DU145 and PC3 cells after transfected with conditional overexpressing-vector of PAGE4. b Protein expression of PAGE4 in PAGE4-transfected 22RV1 cells with or without treatment of $\mathrm{H}_{2} \mathrm{O}_{2}$. $\mathbf{c} \mathbf{d}$ mRNA expression of PAGE4 in PAGE4-transfected DU145 and PC3 cells after $\mathrm{H}_{2} \mathrm{O}_{2}$ stimulation, ${ }^{*} P<0.05$. e DU145 and LNCaP cells were co-transfected PAGE4 with either CLK2 or HIPK1. Cells were treated with $\mathrm{H}_{2} \mathrm{O}_{2}$ stimulation, and the intracellular $\mathrm{ROS}$ were measured, ${ }^{*} P<0.05$. All experiments were repeated at least 3 times

Next, to test DNA damage, a comet assay was performed in DU145 and PC3 cell lines with or without PAGE4 overexpression after exposed to $\mathrm{H}_{2} \mathrm{O}_{2}$ for $12 \mathrm{~h}$. As shown in Fig. 3, a lower level of DNA damage was found in PAGE4 overexpressing cell lines when compared with empty vector-transfected cell lines, indicated by shorter tails and smaller tail DNA percentage in PAGE4 overexpressing cell lines. At the same time, in a flow cytometry, PAGE4 overexpressing cell lines also showed a remarkable low level of apoptosis when exposed to $\mathrm{H}_{2} \mathrm{O}_{2}$ compared to empty vector-transfected cell lines (Fig. 4). Above all, the overexpression of PAGE4 in prostate cancer cell lines can protect cancer cells from cell death that is caused by oxidative stress through reducing DNA damage.
Overexpressing PAGE4 promotes tumor growth in vivo Having known that PAGE4 can protect prostate cancer cells from oxidative stress in vitro, we further investigated whether PAGE4 promotes tumor growth in vivo. As shown in Fig. 5 a, b, PAGE4-overexpressing cells formed larger tumors in SCID mice than cells without PAGE4 overexpression, while the body weight of mice were not much different between three groups during the whole experiment (Additional file 3: Figure S2). These results suggest that PAGE4 overexpression in vivo indeed enhances tumor growth in mice. Given that proliferating cancer cells may suffer a high oxidative stress in vivo, we ask whether ROS level in the body of mice affect tumor growth. When we treated the mice with antioxidant NAC, we found that the promoting effect of 

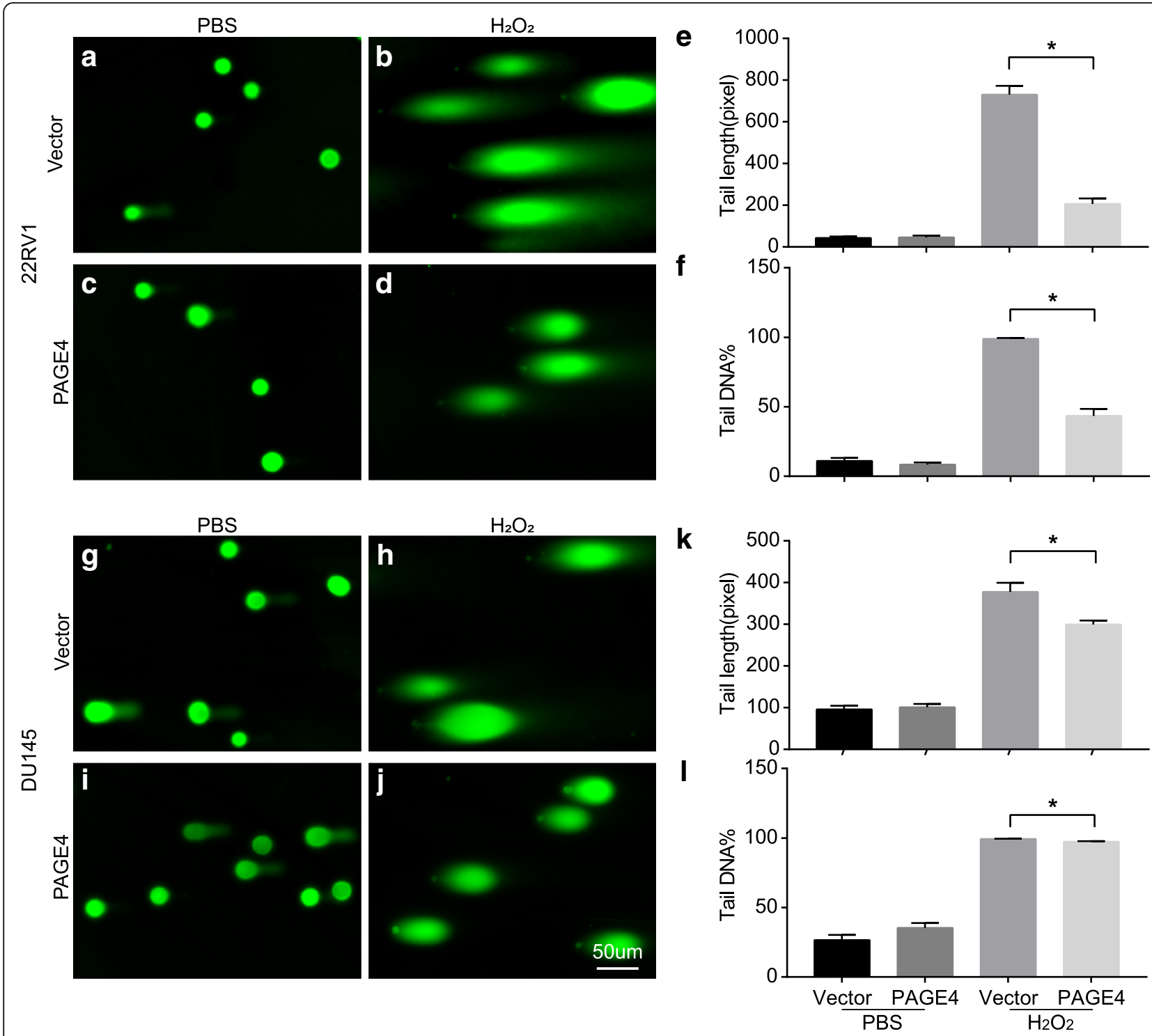

Fig. 3 Alkaline comet assay for PAGE4 overexpressed cells when exposed to $\mathrm{H}_{2} \mathrm{O}_{2}$. a-d Representative images of comets assay in 22RV1 cells that were transfected with either PAGE4 or empty vector and treated with PBS or $\mathrm{H}_{2} \mathrm{O}_{2}$. e The statistical analysis of tail length. $\mathbf{f}$ The statistical analysis of tail DNA percentage, ${ }^{*} P<0.05$. g-j Representative images of comets assay in DU145 cells that were transfected with either PAGE4 or empty vector and treated with PBS or $\mathrm{H}_{2} \mathrm{O}_{2}$. $\mathbf{k}$ The statistical analysis of tail length. I The statistical analysis of tail DNA percentage, ${ }^{*} P<0.05$. All experiments were repeated 3 times and at least 30 cells per group were counted

PAGE4 overexpression on tumor growth was partially impeded (Fig. 5 a, b). At the same time, in consistence with the above in vitro study (Fig. 1), PAGE4 mRNA expression in tumor tissues was also significantly inhibited by NAC treatment in mice, although the transcription of PAGE4 is largely derived from the exogenous construct, namely PAGE4-overexpressing vector (Fig. 5 c). These results reveal that PAGE4 is an indeed ROS-response gene and can promote tumor growth when induced by ROS stress.

In addition, several genes that were reported to be related to a less cancer aggressiveness or metastatic potential were found to be increased upon PAGE4 overexpression, including ACTA2, FBLN1 and F2R (Fig. 5 d, e, f). This result may suggest that PAGE4 overexpression enhance tumor growth but not cancer aggressiveness.

\section{PAGE4 regulation under oxidative stress is related to MAPK pathway}

To investigate how PAGE4 is involved in cell survival under oxidative stress, we preformed RNA sequencing in 22RV1 and DU145 cells with or without PAGE4 overexpression after $\mathrm{H}_{2} \mathrm{O}_{2}$ treatment. Totally, 4726 DEGs were found in 22RV1 cells and 2826 


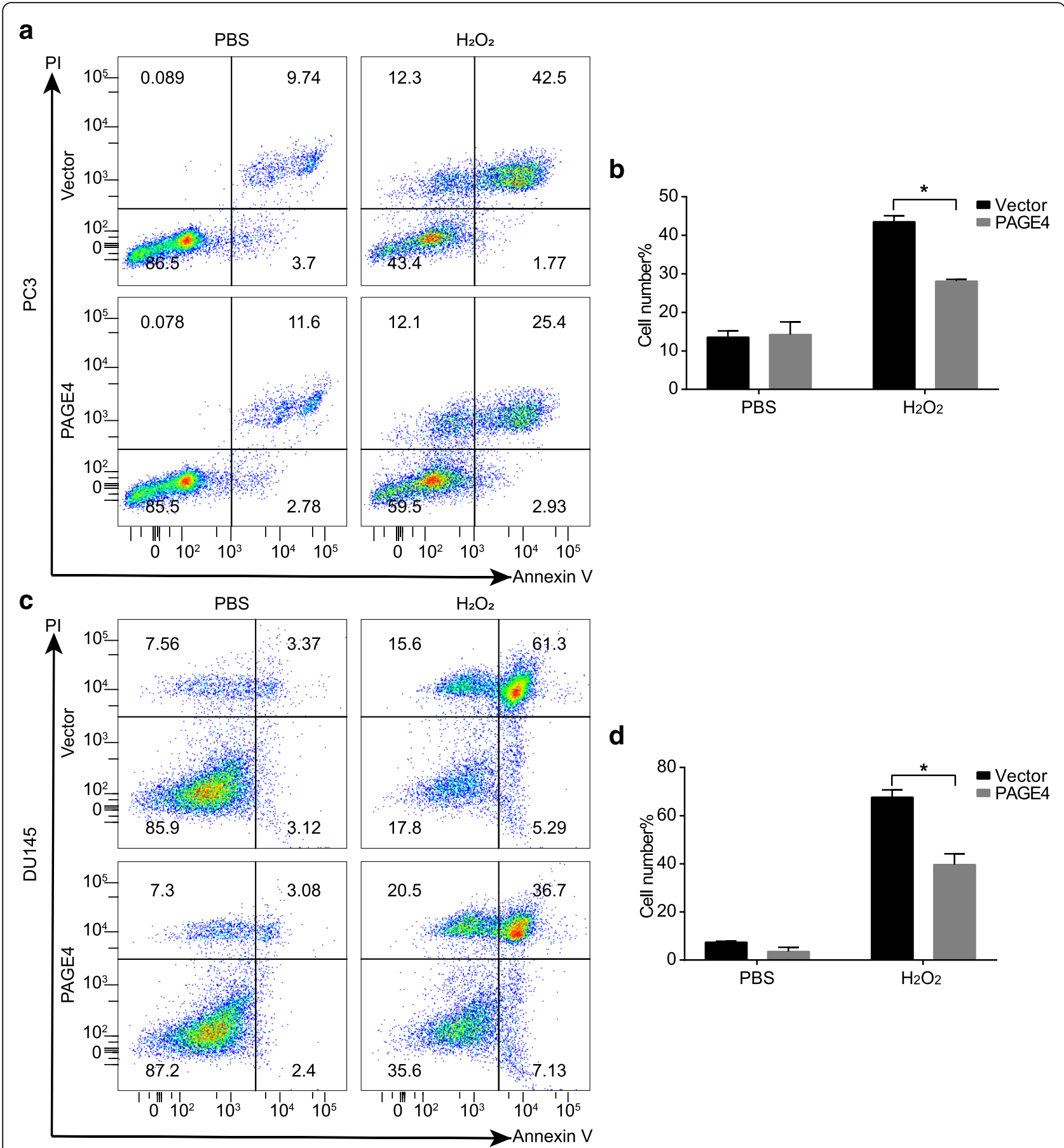

Fig. 4 Apoptosis analysis for PAGE4 overexpressing cells when exposed to $\mathrm{H}_{2} \mathrm{O}_{2}$. a PC3 cells with or without PAGE4 overexpression were stained with Annexin V/PI. The percentage of apoptotic cells was calculated using flow cytometry. $\mathbf{b}$ The statistical analysis of apoptosis assay results, ${ }^{*} P<0.05$. c DU145 cells with or without PAGE4 overexpression were stained with Annexin V/PI. The percentage of apoptotic cells was calculated using flow cytometry. $\mathbf{d}$ The statistical analysis of apoptosis assay results, ${ }^{*} P<0.05$. Experiments were repeated 3 times

DEGs in DU145 cells when comparing those with or without PAGE4 overexpression (Fig. 6 a). Among these DEGs, 425 are shared in both 22RV1 and DU145 cells (Additional file 4: Table S2).
GSEA analysis showed that these DEGs were enriched in the pathways involved in DNA damage repair (Fig. 6 b). DNA damage and repair genes were previously reported to impact the metastatic potential of prostate 
a

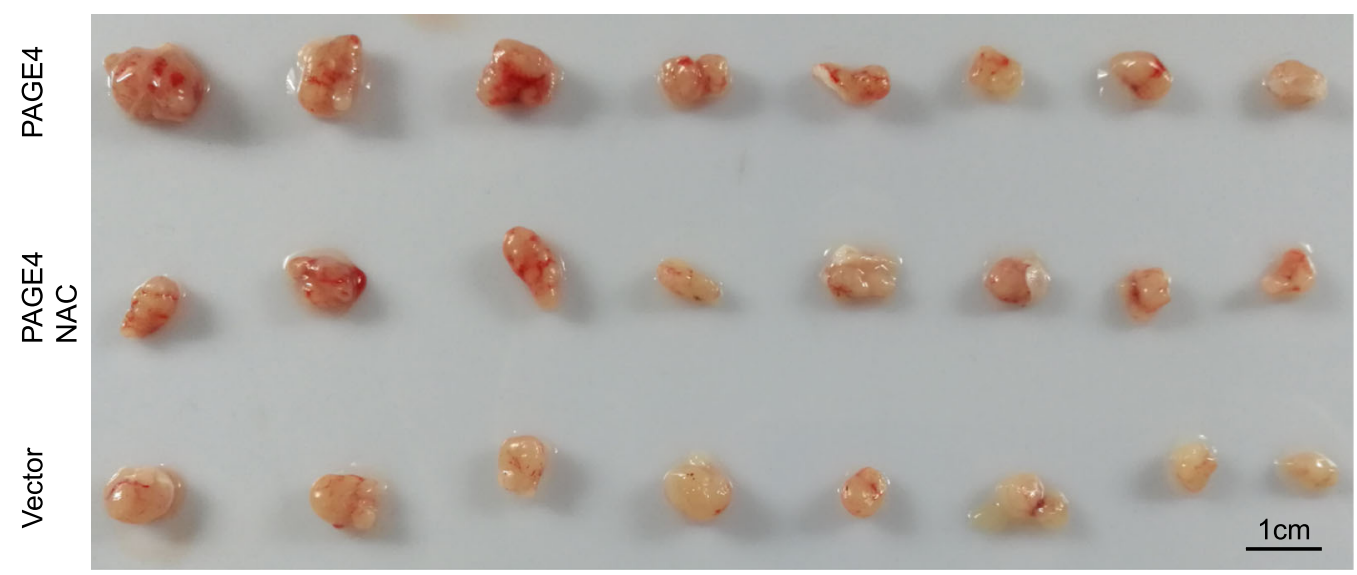

b

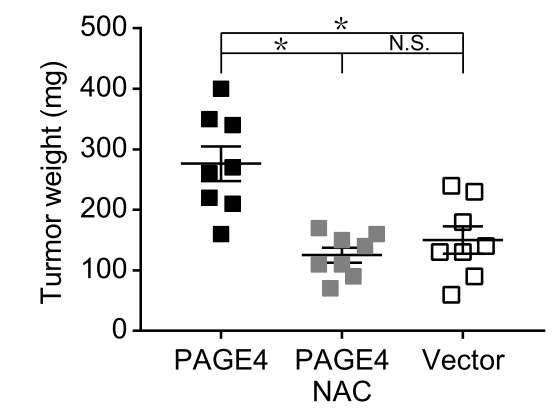

d

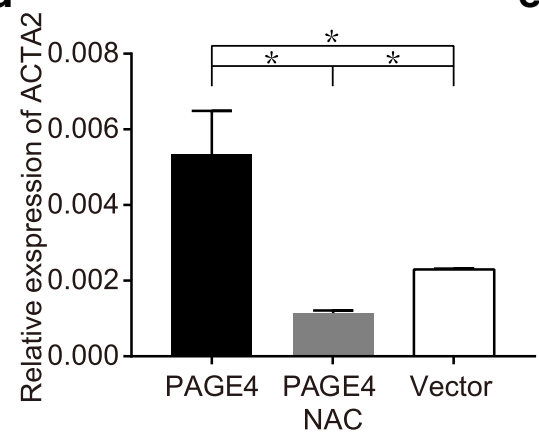

C

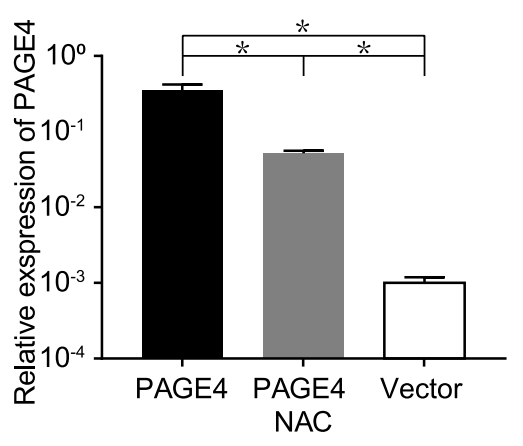

e

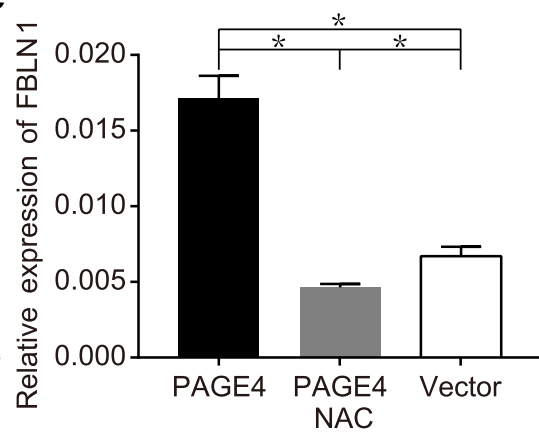

f

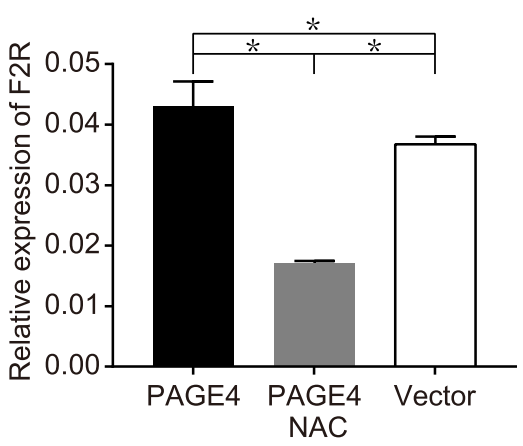

Fig. 5 PAGE4 promotes prostate cancer cell growth but reduce tumor malignancy in vivo. a Tumor formation of DU145 cells with or without PAGE4 overexpression. Mice were feed with DOX in drinking water and NAC was administered by intraperitoneal injection. b Tumor weight in different groups, $n=8$ in each group, ${ }^{*} P<0.05$. $\mathbf{c}$ Expression of PAGE4 in xenografted tumor tissues was measured with $Q-P C R,{ }^{*} P<0.05$. $\mathbf{d}$ Expression of ACTA2 in xenografted tumor tissues was measured with Q-PCR, ${ }^{*} P<0.05$. e Expression of FBLN1 in xenografted tumor tissues was measured with $\mathrm{Q}-\mathrm{PCR},{ }^{*} P<0.05$. $\mathbf{f}$ Expression of F2R in xenografted tumor tissues was measured with $\mathrm{Q}-\mathrm{PCR},{ }^{*} P<0.05$. Three tumors were randomly picked and subjected to Q-PCR assay

cancer cells [40], here we found that cells overexpressing PAGE4 exhibited a gene expression pattern somehow of a low metastatic potential (Additional file 5: Figure S3a). In support, by analysing TCGA data, we found that patients with high expression of PAGE4 in tumor tissues had longer disease-free survival (DFS) time than those with low PAGE4 expression (Additional file 5: Figure S3b).

Next, we conducted Metascape [41] pathway analysis [42] on 425 DEGs and found that the enriched pathways can be clustered in 17 groups (Fig. 6 c). Further, we focused on genes enriched in positive regulation of MAPK cascade, namely BMP4, CHRNA7, EPHA8, F2R, IGF2, TBX1, WNT5A, RASSF2, NOX1, GHRL and PELI2 (Fig. 6 d, e).

\section{PAGE4 regulates MAPK pathway}

Based on the results of RNA sequencing, we next explored how genes in MAPK pathway are regulated by PAGE4 under oxidative stress. When exposed to $\mathrm{H}_{2} \mathrm{O}_{2}$, 


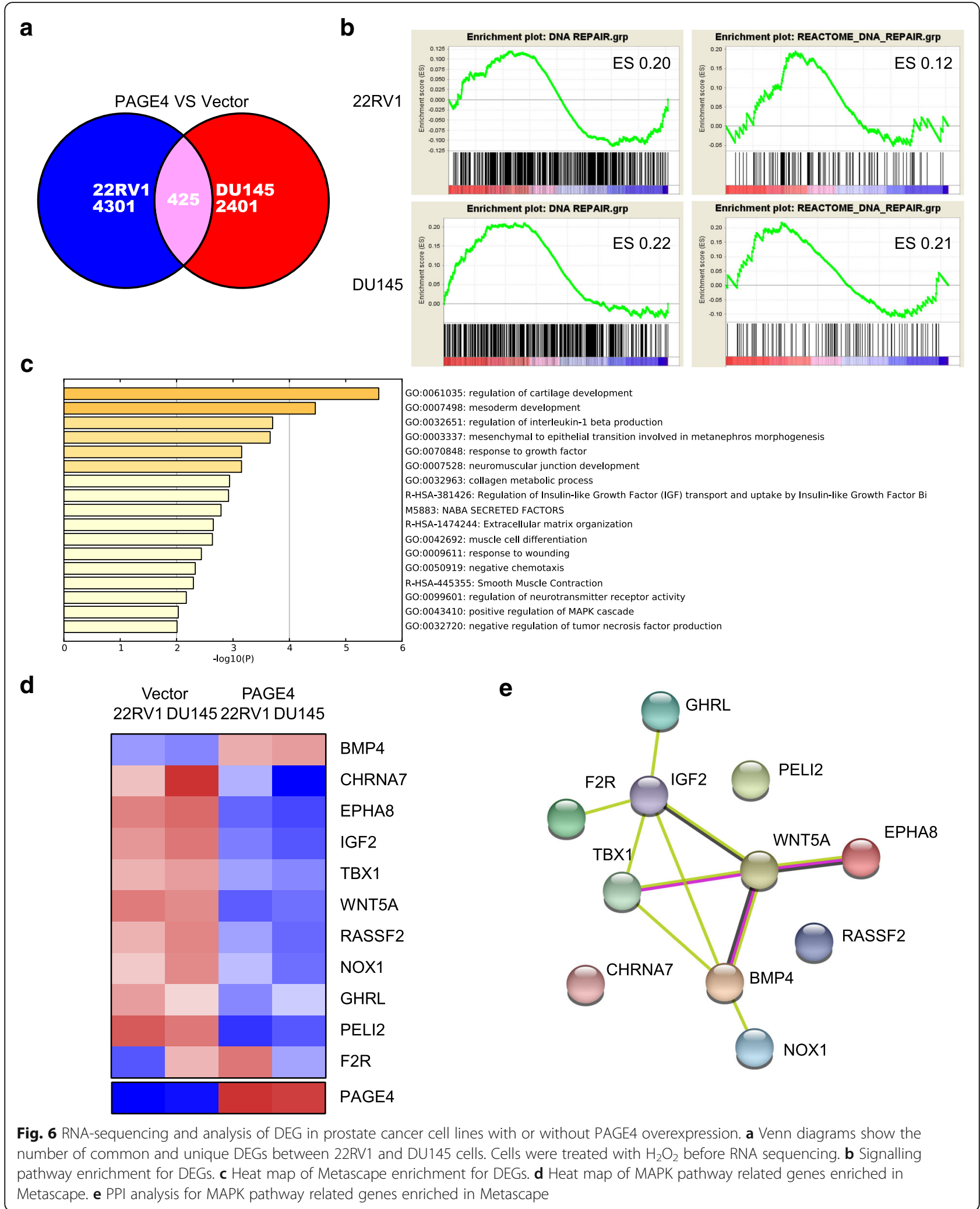


all cell lines showed activation of MAPK pathway marked by increased phosphorylation of MAP2K4, JNK, and c-JUN but decreased phosphorylation of ATF2, suggesting that oxidative stress effectively induce MAPK pathway signalling in these cells. In cells with PAGE4 overexpression, there was a lower phosphorylation of MAP2K4, JNK and c-JUN than control groups (line 4 comparing to line 3 in Fig. 7 a), suggesting that PAGE4 may reduce cell death through suppressing the activation of JNK.

Another key factor in MAPK pathway is ERK 1/2, which helps cells survive [43, 44]. Here we found that phosphorylated ERK $1 / 2$ was significantly increased in PAGE4 overexpressing cells, no matter whether $\mathrm{H}_{2} \mathrm{O}_{2}$ was added. This may suggest that PAGE4 is involved in ERK $1 / 2$ phosphorylation separately from ROS status. On the other hand, after $\mathrm{H}_{2} \mathrm{O}_{2}$ treatment, total ERK was decreased in both PAGE4 overexpressing and control cells, while phosphorylated ERK $1 / 2$ was increased in both cells, with particular enhancement in PAGE4 overexpressing cells. To some extent, this result may suggest that ERK $1 / 2$ phosphorylation which is likely a survival signalling of cells under ROS stress is much enhanced by PAGE4 overexpression. Thus, elevated of ERK 1/2 phosphorylation induced by overexpression of PAGE4 may be a mechanism of cell survival under oxidative stress. Furthermore, we examined the protein expression of PAGE4 and phosphorylated ERK1/2 in prostate cancer tissues. To support our hypothesis, the two proteins were largely co-expressed in either prostate cancer cells or normal prostate epithelia (Fig. 7 b), suggesting a potential association of PAGE4 function with the activation of MAPK pathway.

Taken together, as shown in Fig. 7 c, it is speculated that oxidative stress induce cell death partly through activating the JNK pathway which has been known to be able to trigger apoptotic cascade. In contrast, ERK that promotes cell survival is also activated during ROS stress to balance the cell death. In this context, PAGE4 protect cells from oxidative stress potentially by reducing cell death message while enhancing cell survival signals.

\section{Discussion}

It is well known that, in the aged prostate where prostate cancer is most often developed, cells are commonly suffered a heavy oxidative stress due to aging [45], smoking $[46,47]$ as well as obesity [48]. In addition, cancer cells keep proliferating under a hypoxia condition, which itself produces more ROS than normal condition. Apparently, the oxidative stresses existing in the tumor microenvironment is a double-blade sword. On one side, ROS kills cells by inducing apoptosis, while on the other side, ROS remodels cells by causing more harmful DNA mutation [49], which eventually drive an aggressive cancer. For example, ROS in the prostate has been shown to promote epithelial cells transformation [50]. In this scenario, antioxidants or protection of ROS may play a dual role either, in that enhancing cell survival and reducing harmful DNA damage, which may lead to an attenuated cancer evolution towards more aggressive phenotype in a microenvironment enriched with ROS pressure $[40,51,52]$.

In the present study, we found that PAGE4 worked exactly in this protective way in PCa cells under oxidative stress status. Firstly, ROS induced PAGE4 expression, which in turn protected cells from apoptosis and DNA damage in vitro and promoted tumor growth in vivo. However, when we checked the expression of several tumor less aggressiveness-related genes, such as ACTA2 [53], FBLN1 [54], F2R [55], we found that the expressions of these genes were increased upon overexpression of PAGE4. In addition, RNA sequencing data confirmed that a panel of metastasis-related genes were attenuated in PAGE4 overexpressing cells. In support, higher expression of PAGE4 predicted a better DFS of PCa in TCGA dataset, adhering to its inhibitory role of tumor aggressiveness. This is consistent with our previous finding that PAGE4 mRNA level was among markers correlated with a good prognosis of $\mathrm{PCa}$ [14]. Additionally, the previous finding that PAGE4 protein was detected more often in localized PCa than metastatic cancer highlights again the reverse correlation between PAGE4 expression and cancer aggressive phenotype [10]. Intriguingly, a recent elegant study links PAGE4 to the dynamic androgen-dependence and speculates that PAGE4 interacts with particular kinase suppresses AR hyperactivity and therefore makes cells sensitive to androgen deprivation (ADT) treatment [13], which may certainly lead to longer DFS. However, given that many metastatic PCa that are lack of PAGE4 expression are sensitive to ADT initially, it still could not be excluded that PAGE4 impacts cancer aggressiveness beyond ADT sensitivity. Thus, it is possible that PAGE4 blocks the development of aggressive $\mathrm{PCa}$ through attenuating the cell damage caused by oxidative stress which exists in the tumor microenvironment. To this rate, PAGE4 expression in PCa cells is potentially to be a predictive biomarker for good cancer prognosis, although it might promote tumor growth in primary site.

In consistent with our previous finding that PAGE4 is a stress-response protein [10], we here confirmed that PAGE4 expression was remarkably induced by ROS stimuli not only in cell models but also in xenografted tumor tissues. Notably, both endogenous PAGE4 expression and exogenously transfected PAGE4 construct can be induced by $\mathrm{H}_{2} \mathrm{O}_{2}$. This phenomenon was also noticed in our previous study, in which exogenously expressed PAGE4 was increased after treating cells with TNF- $\alpha$ 


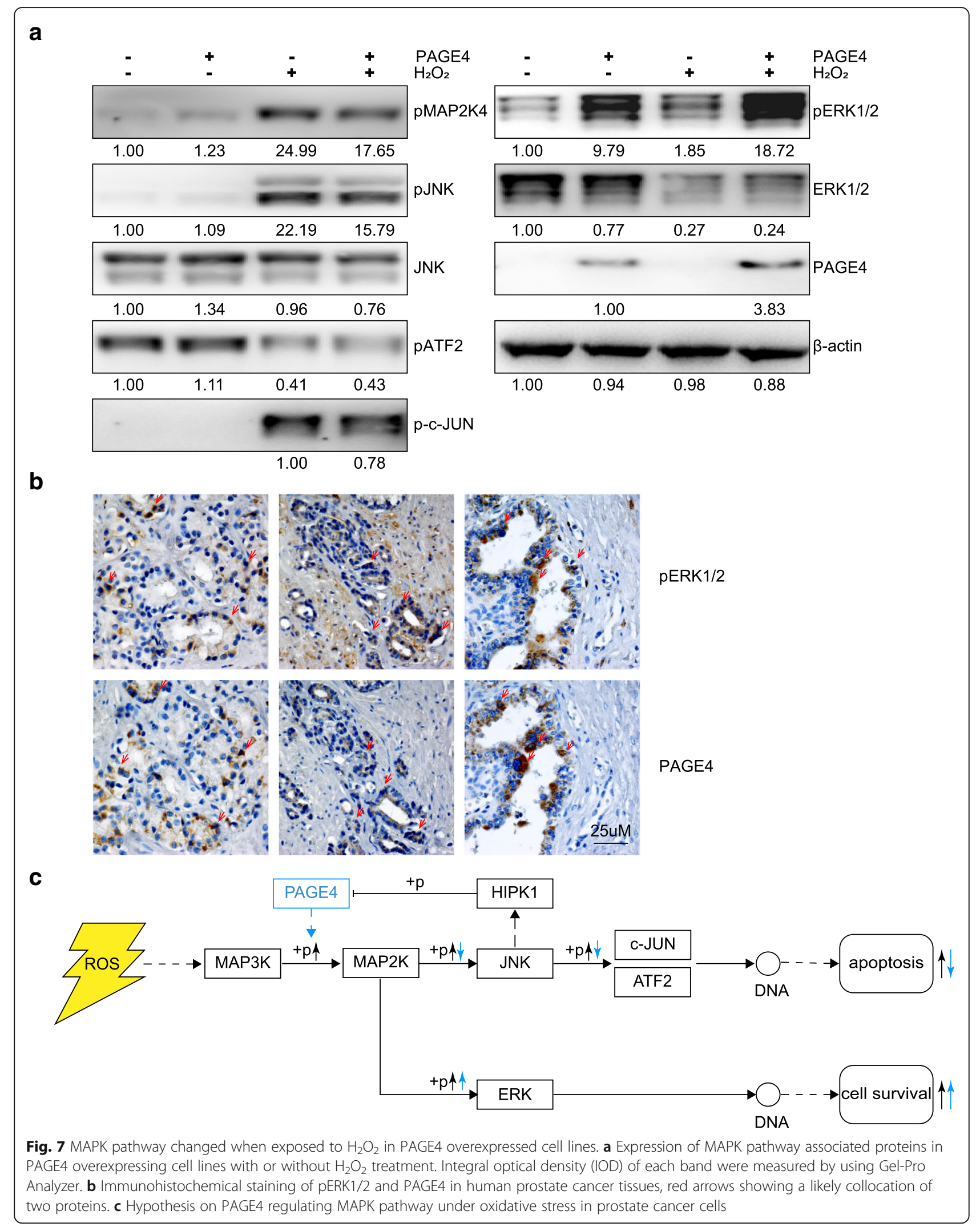


that is a typical inflammatory chemokine [10]. These results consistently indicate that a post-transcriptional regulation may play an important role in up-regulating the expression of PAGE4 in response to stress stimuli.

Interestingly, PAGE4 has been shown to be interacted with two kinases, HIPK1 and CLK2, and leads to opposing functions. Particularly, CLK2 hyperphosphorylates PAGE4 resulting in attenuated function and likely rapid degradation [13]. In consistent with this result, we here found that co-expression of CLK2 with PAGE4 eliminated the effect of PAGE4 overexpression alone on reducing ROS production under oxidative stress. Notably, the inhibitory effect of CLK2 on PAGE4 function is similar in two PCa cells with different AR activity. However, the impact of HIPK1 on PAGE4 function is largely cell type-specific, namely enhancing PAGE4 protection on ROS in LNCaP cells that express functional AR but attenuating PAGE4 function in DU145 cells, in which AR is silenced. Given that it has been shown that HIPK1-PAGE4 interaction may affect AR activity in PCa cells [13], it is not surprise to observe that HIPK1 impacts PAGE4 activity in an AR-related manner, although many other differences in two cells may also potentially impact the interaction between PAGE4 and HIPK1. For example, HIPK1 has been shown to be activated by MAPK pathway and involved in ROS-induced cell death [56-58], while MAPK proteins associated with the HIPK1were more often mutated in DU145 but not in LNCaP cells [59]. Clearly, the interaction between PAGE4 and its catalysts under ROS stress should be further investigated.

In the present study, we found that PAGE4 significantly protected cell from DNA damage and cell death caused by ROS stress in cell models. The GSEA enrichment of DEGs also confirmed the protective effect of PAGE4 on DNA repair genes. Additionally, PAGE4 was found to promote tumor growth in vivo. It may be expected that cells suffer a high level of oxidative stress when growing in vivo, and ROS inhibition may reduce cell death caused by ROS and promote tumor growing. However, when we used NAC to neutralize ROS in the body of mice, the growth of xenografted tumors was likely to be impeded. To test, we found that NAC treatment significantly inhibited the expression of PAGE4 in tumor tissues. The decreased expression of PAGE4 following NAC treatment might partly explain why the growth of tumor was impeded but not promoted in this group, because PAGE4 was highly forced expressed in the tumors in the present study and its effect on protecting cell death and promoting cell survival is overwhelming compared to the effect of endogenous ROS on inducing cell death. Therefore, it is likely that the decreased expression of PAGE4 caused by ROS inhibition results in less cell survival, which is proposed to be more profound than the direct effect of ROS inhibition on reducing cell death. Consequently, the net result of NAC treatment on PAGE4 overexpressing-tumors would be the less cell survival, namely an impeded tumor growing. By all means, it is reasonable to speculate that the artificially enforced overexpression of PAGE4 in xenografted tumor would not completely mimic the pathological function of PAGE4 that is endogenously induced by microenvironmental ROS. In any rate, in this in vivo experiment, we observed the direct effect of PAGE4 overexpression on tumor survival, and we also confirmed that lowering ROS level in tumor tissue indeed decreased the expression of PAGE4, which nicely agrees with the stress-response role of PAGE4 to ROS.

In exploring the context of PAGE4 regulation on cell fate, RNA sequencing was conducted. We found a likely activation of MAPK pathway in PAGE4 overexpressing cell lines when they experienced ROS stress. It has been known that the MAPK signalling pathway regulates cellular process in varied aspects including cell proliferation, differentiation, mitosis, cell survival, and apoptosis [60]. Upregulation of JNK, a downstream gene in MAPK pathway, can cause apoptosis [43, 61]. Previous study showed that PAGE4 may interact with c-JUN and activate MARK pathway [20]. In the present study, MAPK/ JNK pathway was activated after $\mathrm{H}_{2} \mathrm{O}_{2}$ treatment, while this activation was slightly lower in PAGE4 overexpressing cells than empty vector-transfected cell lines. This result suggests an attenuated apoptosis-inducing effect of ROS by PAGE4 overexpression. On the other hand, while activating of ERK $1 / 2$ is known to promote cell survival under ROS stress [43, 44], here we found that ERK1/2 was greatly activated by PAGE4 overexpression. Supportively, activated ERK1/2 was found to be largely colocalized with PAGE4 in human prostate tissue samples. These results strongly support the promoting effect of PAGE4 on cell survival. Further study should be warranted on the potential interaction between PAGE4 and ERK1/2 activation.

\section{Conclusions}

In conclusion, the present study demonstrates the protective effects of PAGE4 in prostate cancer cells when exposed to oxidative stress. PAGE4 functions potentially through attenuating the phosphorylation of JNK to reduce apoptosis, and enhancing the phosphorylation of ERK to help cells survive. Clinically, the protection of PAGE4 on ROS stress may be translated into the less harmful DNA damage induced by ROS and therefore resulting in less chance to accumulate mutations to develop an aggressive cancer. Thus, a high expression of PAGE4 in PCa tissues may serve as a potential biomarker for better cancer prognosis. 


\section{Additional files}

Additional file 1: Table S1. Primers for Q-RT-PCR that were used in this article. (XLS $43 \mathrm{~kb}$ )

Additional file 2: Figure S1. ROS analysis in cells after $\mathrm{H}_{2} \mathrm{O}_{2}$ stimulate (PDF $78 \mathrm{~kb}$ )

Additional file 3: Figure S2. Mice weight during the experiment. (PDF $75 \mathrm{~kb}$ ) Additional file 4: Table S2. 425 shared DEGs in 22RV1 and DU145 cell lines. (XLS 90 kb)

Additional file 5: Figure S3. PAGE4 shows low tumor malignancy. a Heat map for several prostate cancer malignancy related genes. b Disease-free survival analysis of PAGE4 in TCGA dataset. (PDF 91 kb)

\section{Abbreviations}

ACTB: Actin Beta; BMP4: Bone morphogenetic protein 4; BPH: Benign prostatic hyperplasia; CRPC: Castration resistant prostate cancer; CTA: Cancer testis antigen; DEG: Differentially expressed genes; DOX: Doxycycline; ERK: Extracellular signal-regulated kinase; GSEA: Gene Set Enrichment Analysis; HIPK1: Homeodomain-interacting protein kinase 1; IDP: Intrinsic disorder protein; JNK: JUN N-Terminal Kinase; MAP2K4: Mitogen-Activated Protein Kinase Kinase 4; MAPK: Mitogen-activated protein kinase; NAC: NAcetyl-L-cysteine; PAGE4: Prostate Associate Gene 4; PCa: Prostate cancer; PCR: Polymerase Chain Reaction; PI: Propidine iodide; ROS: Reactive oxygen species; SCID: Severe combined immunodeficiency; SEM: Standard Error of Mean; SOD1: Superoxide Dismutase 1; TGF- 31 : Transforming growth factor beta 1; TNFa: Tumor Necrosis Factor

\section{Acknowledgments}

Not applicable.

\section{Funding}

This work was supported by grants from the National Natural Science Foundation of China (No. 81372766 and No. 81572532), and the Liaoning "Climbing" scholarship.

\section{Availability of data and materials}

The datasets supporting the findings of this study are included within the article.

\section{Authors' contributions}

ZY, LCC and FS designed the study; LCC, FS and DQZ performed the experiments; $Y Z$ and $Z G$ J analysed the data; LCC, FS, KCZ and ZY wrote the manuscript. $F C$ and $Z Y$ reviewed the manuscript. All authors have read and approved the final manuscript.

\section{Ethics approval and consent to participate}

This study has been conducted in accordance with ethical standards and the national and international guidelines. All animal experiments were carried out according to the protocol approved by the China Medical University Guidelines for Use and Care of Animals. This study was approved by the Research Ethics Committee of China Medical University and all patients signed the written informed consent.

\section{Consent for publication}

Not applicable.

\section{Competing interests}

The authors declare that they have no competing interests.

\section{Publisher's Note}

Springer Nature remains neutral with regard to jurisdictional claims in published maps and institutional affiliations.

\section{Author details}

'Department of Urology, Cancer Hospital of China Medical University, Liaoning Cancer Hospital and Institute, 44 Xiaoheyan Road, Shenyang 110042, Liaoning, China. ${ }^{2}$ Department of Urology, The First Hospital of China Medical University, 155 Nanjing North Road, Shenyang 110001, Liaoning, China
Received: 24 August 2018 Accepted: 9 January 2019

Published online: 18 January 2019

\section{References}

1. Siegel RL, Miller KD, Jemal A. Cancer statistics, 2017. CA Cancer J Clin. 2017; 67(1):7-30.

2. Beltran H, Prandi D, Mosquera JM, Benelli M, Puca L, Cyrta J, Marotz C, Giannopoulou E, Chakravarthi BV, Varambally S, et al. Divergent clonal evolution of castration-resistant neuroendocrine prostate cancer. Nat Med. 2016;22(3):298-305.

3. Molania R, Mahjoubi F, Mirzaei R, Khatami SR, Mahjoubi B. A panel of Cancer testis antigens and clinical risk factors to predict metastasis in colorectal Cancer. J Biomark. 2014;2014:272683.

4. Chen Z, Li M, Yuan Y, Wang Q, Yan L, Gu J. Cancer/testis antigens and clinical risk factors for liver metastasis of colorectal cancer: a predictive panel. Dis Colon Rectum. 2010;53(1):31-8.

5. Minnery $\mathrm{CH}$, Getzenberg $\mathrm{RH}$. Benign prostatic hyperplasia cell line viability and modulation of jm-27 by doxazosin and ibuprofen. J Urol. 2005;174(1): 375-9.

6. lavarone C, Wolfgang C, Kumar V, Duray P, Willingham M, Pastan I, Bera TK. PAGE4 is a cytoplasmic protein that is expressed in normal prostate and in prostate cancers. Mol Cancer Ther. 2002;1(5):329-35.

7. Prakash K, Pirozzi G, Elashoff M, Munger W, Waga I, Dhir R, Kakehi Y, Getzenberg RH. Symptomatic and asymptomatic benign prostatic hyperplasia: molecular differentiation by using microarrays. Proc Natl Acad Sci U S A. 2002:99(11):7598-603.

8. Suyama T, Shiraishi T, Zeng Y, Yu W, Parekh N, Vessella RL, Luo J, Getzenberg RH, Kulkarni P. Expression of cancer/testis antigens in prostate cancer is associated with disease progression. Prostate. 2010;70(16):1778-87.

9. Shah US, Arlotti J, Dhir R, Lu S, Pirozzi G, Prakash K, Getzenberg RH. Androgen regulation of JM-27 is associated with the diseased prostate. J Androl. 2004;25(4):618-24.

10. Zeng Y, Gao D, Kim JJ, Shiraishi T, Terada N, Kakehi Y, Kong C, Getzenberg $\mathrm{RH}$, Kulkarni P. Prostate-associated gene 4 (PAGE4) protects cells against stress by elevating p21 and suppressing reactive oxygen species production. Am J Clin Exp Urol. 2013;1(1):39-52.

11. Sampson N, Untergasser G, Lilg C, Tadic L, Plas E, Berger P. GAGEC1, a cancer/testis associated antigen family member, is a target of TGF-beta1 in age-related prostatic disease. Mech Ageing Dev. 2007;128(1):64-6.

12. Sampson N, Ruiz C, Zenzmaier C, Bubendorf L, Berger P. PAGE4 positivity is associated with attenuated $A R$ signaling and predicts patient survival in hormone-naive prostate cancer. Am J Pathol. 2012;181(4):1443-54.

13. Kulkarni $P$, Jolly MK, Jia D, Mooney SM, Bhargava A, Kagohara LT, Chen Y, Hao P, He Y, Veltri RW, et al. Phosphorylation-induced conformational dynamics in an intrinsically disordered protein and potential role in phenotypic heterogeneity. Proc Natl Acad Sci U S A. 2017;114(13):E2644-53.

14. Shiraishi T, Terada N, Zeng Y, Suyama T, Luo J, Trock B, Kulkarni P, Getzenberg RH. Cancer/testis antigens as potential predictors of biochemical recurrence of prostate cancer following radical prostatectomy. J Transl Med. 2011:9:153.

15. Takahashi S, Shiraishi T, Miles N, Trock BJ, Kulkarni P, Getzenberg RH. Nanowire analysis of cancer-testis antigens as biomarkers of aggressive prostate cancer. Urology. 2015;85(3):704.e701-7.

16. Zeng Y, He Y, Yang F, Mooney SM, Getzenberg RH, Orban J, Kulkarni P. The cancer/testis antigen prostate-associated gene 4 (PAGE4) is a highly intrinsically disordered protein. J Biol Chem. 2011;286(16):13985-94.

17. Kulkarni P. Intrinsically disordered proteins and prostate cancer: pouring new wine in an old bottle. Asian J Androl. 2016;18(5):659-61.

18. Mooney SM, Qiu RY, Kim JJ, Sacho EJ, Rajagopalan K, Johng D, Shiraishi T, Kulkarni P, Weninger KR. Cancer/testis antigen PAGE4, a regulator of C-Jun transactivation, is phosphorylated by homeodomain-interacting protein kinase 1, a component of the stress-response pathway. Biochemistry. 2014; 53(10):1670-9.

19. He Y, Chen Y, Mooney SM, Rajagopalan K, Bhargava A, Sacho E, Weninger K Bryan PN, Kulkarni P, Orban J. Phosphorylation-induced conformational ensemble switching in an intrinsically disordered Cancer/testis antigen. J Biol Chem. 2015;290(41):25090-102.

20. Rajagopalan K, Qiu R, Mooney SM, Rao S, Shiraishi T, Sacho E, Huang H, Shapiro E, Weninger KR, Kulkarni P. The stress-response protein prostateassociated gene 4 , interacts with c-Jun and potentiates its transactivation. Biochim Biophys Acta. 2014;1842(2):154-63. 
21. Kwon M, Firestein BL. DNA transfection: calcium phosphate method. Methods Mol Biol. 2013;1018:107-10.

22. Spandidos A, Wang $X$, Wang H, Seed B. PrimerBank: a resource of human and mouse PCR primer pairs for gene expression detection and quantification. Nucleic Acids Res. 2010;38(Database issue):D792-9.

23. PrimerBank PCR Primers for Gene Expr Detection and Quantification. https:// pga.mgh.harvard.edu/primerbank/index.html. Accessed 3 Jan. 2017.

24. Mahdavinezhad A, Yadegarazari R, Mousavi-Bahar SH, Poorolajal J, Jafari M, Amirzargar MA, Effatpanah H, Saidijam M. Evaluation of zinc finger E-box binding homeobox 1 and transforming growth factor-beta2 expression in bladder cancer tissue in comparison with healthy adjacent tissue. Investig Clin Urol. 2017;58(2):140-5.

25. Jamialahmadi K, Soltani F, Nabavi Fard M, Behravan J, Mosaffa F. Assessment of protective effects of glucosamine and $\mathrm{N}$-acetyl glucosamine against DNA damage induced by hydrogen peroxide in human lymphocytes. Drug Chem Toxicol. 2014;37(4):427-32.

26. Cramer SL, Saha A, Liu J, Tadi S, Tiziani S, Yan W, Triplett K, Lamb C, Alters SE, Rowlinson S, et al. Systemic depletion of L-cyst(e)ine with cyst(e)inase increases reactive oxygen species and suppresses tumor growth. Nat Med. 2017;23(1):120-7.

27. Redelsperger IM, Taldone T, Riedel ER, Lepherd ML, Lipman NS, Wolf FR. Stability of doxycycline in feed and water and minimal effective doses in tetracycline-inducible systems. J Am Assoc Lab Anim Sci. 2016;55(4):467-74.

28. Bosgelmez II, Guvendik G. N-acetyl-L-cysteine protects liver and kidney against chromium(VI)-induced oxidative stress in mice. Biol Trace Elem Res. 2017;178(1):44-53

29. Kim D, Langmead B, Salzberg SL. HISAT: a fast spliced aligner with low memory requirements. Nat Methods. 2015;12(4):357-60.

30. Liao Y, Smyth GK, Shi W. featureCounts: an efficient general purpose program for assigning sequence reads to genomic features. Bioinformatics. 2014;30(7):923-30.

31. Love MI, Huber W, Anders S. Moderated estimation of fold change and dispersion for RNA-seq data with DESeq2. Genome Biol. 2014;15(12):550.

32. $\mathrm{PGC}-1 \mathrm{a}-$-responsive genes involved in oxidative phosphorylation are coordinately downregulated in human diabeteset al. Subramanian A, Tamayo P, Mootha VK, Mukherjee S, Ebert BL, Gillette MA, Paulovich A, Pomeroy SL, Golub TR, Lander ES, Gene set enrichment analysis: a knowledge-based approach for interpreting genome-wide expression profiles. Proc Natl Acad Sci U S A. 2005;102(43):15545-50.

33. Gene Set Enrichment Analysis. http://software.broadinstitute.org/gsea/index. jsp. Accessed 8 Mar 2018.

34. String. https://string-db.org. Accessed 29 July 2019.

35. Genomic Data Commons Data Portal. https://portal.gdc.cancer.gov/projects/ TCGA-PRAD. Accessed 3 Apr 2018.

36. R packages for survival analysis https://CRAN.R-project.org/view=Survival. Accessed 3 Apr 2018.

37. Lopez-Otin C, Blasco MA, Partridge L, Serrano M, Kroemer G. The hallmarks of aging. Cell. 2013;153(6):1194-217.

38. Hoeijmakers JH. DNA damage, aging, and cancer. N Engl J Med. 2009; 361(15):1475-85.

39. Kulkarni P, Dunker AK, Weninger K, Orban J. Prostate-associated gene 4 (PAGE4), an intrinsically disordered cancer/testis antigen, is a novel therapeutic target for prostate cancer. Asian J Androl. 2016;18(5):695-703.

40. Quigley DA, Dang HX, Zhao SG, Lloyd P, Aggarwal R, Alumkal JJ, Foye A, Kothari V, Perry MD, Bailey AM, et al. Genomic hallmarks and structural variation in metastatic prostate Cancer. Cell. 2018;174(3):758-69 e759.

41. Metascape A Gene Annotation \& Analysis Resource. http://metascape.org/ gp/index.html\#/main/step1. Accessed 8 Mar 2018.

42. Tripathi S, Pohl MO, Zhou Y, Rodriguez-Frandsen A, Wang G, Stein DA, Moulton HM, DeJesus P, Che J, Mulder LC, et al. Meta- and orthogonal integration of influenza "OMICs" data defines a role for UBR4 in virus budding. Cell Host Microbe. 2015;18(6):723-35.

43. Xue Z, Vis DJ, Bruna A, Sustic T, van Wageningen S, Batra AS, Rueda OM, Bosdriesz E, Caldas C, Wessels LFA, et al. MAP3K1 and MAP2K4 mutations are associated with sensitivity to MEK inhibitors in multiple cancer models. Cell Res. 2018;28(7):719-29.

44. Khandrika L, Lieberman R, Koul S, Kumar B, Maroni P, Chandhoke R, Meacham RB, Koul HK. Hypoxia-associated p38 mitogen-activated protein kinase-mediated androgen receptor activation and increased HIF-1alpha levels contribute to emergence of an aggressive phenotype in prostate cancer. Oncogene. 2009;28(9):1248-60.
45. Damaschke NA, Yang B, Bhusari S, Svaren JP, Jarrard DF. Epigenetic susceptibility factors for prostate cancer with aging. Prostate. 2013;73(16): 1721-30.

46. Zu K, Giovannucci E. Smoking and aggressive prostate cancer: a review of the epidemiologic evidence. Cancer Causes Control. 2009;20(10):1799-810.

47. Ho T, Howard LE, Vidal AC, Gerber L, Moreira D, McKeever M, Andriole G, Castro-Santamaria R, Freedland SJ. Smoking and risk of low- and high-grade prostate cancer: results from the REDUCE study. Clin Cancer Res. 2014; 20(20):5331-8

48. Maclnnis RJ, English DR. Body size and composition and prostate cancer risk: systematic review and meta-regression analysis. Cancer Causes Control. 2006;17(8):989-1003.

49. Sabharwal SS, Schumacker PT. Mitochondrial ROS in cancer: initiators, amplifiers or an Achilles' heel? Nat Rev Cancer. 2014;14(11):709-21.

50. Gao P, Zhang H, Dinavahi R, Li F, Xiang Y, Raman V, Bhuiwalla ZM, Felsher DW, Cheng L, Pevsner J, et al. HIF-dependent antitumorigenic effect of antioxidants in vivo. Cancer Cell. 2007;12(3):230-8.

51. Schumacker PT. Reactive oxygen species in cancer cells: live by the sword, die by the sword. Cancer Cell. 2006;10(3):175-6.

52. Trachootham D, Zhou Y, Zhang H, Demizu Y, Chen Z, Pelicano H, Chiao PJ, Achanta G, Arlinghaus RB, Liu J, et al. Selective killing of oncogenically transformed cells through a ROS-mediated mechanism by beta-phenylethyl isothiocyanate. Cancer Cell. 2006;10(3):241-52.

53. Yang Z, Peng YC, Gopalan A, Gao D, Chen Y, Joyner AL. Stromal hedgehog signaling maintains smooth muscle and hampers micro-invasive prostate cancer. Dis Model Mech. 2017:10(1):39-52.

54. Schulz WA, Ingenwerth M, Djuidje CE, Hader C, Rahnenfuhrer J, Engers R. Changes in cortical cytoskeletal and extracellular matrix gene expression in prostate cancer are related to oncogenic ERG deregulation. BMC Cancer. 2010;10:505.

55. Wang J, Cai Y, Shao L, Siddiqui J, Palanisamy N, Li R, Ren C, Ayala G, Ittmann M. Activation of NF-\{kappa\}B by TMPRSS2/ERG fusion isoforms through toll-like Receptor-4. Cancer Res. 2011;71(4):1325-33.

56. Sekito A, Koide-Yoshida S, Niki T, Taira T, Iguchi-Ariga SM, Ariga H. DJ-1 interacts with HIPK1 and affects H2O2-induced cell death. Free Radic Res. 2006;40(2):155-65

57. Song JJ, Lee YJ. Role of the ASK1-SEK1-JNK1-HIPK1 signal in Daxx trafficking and ASK1 oligomerization. J Biol Chem. 2003;278(47):47245-52.

58. Li X, Zhang R, Luo D, Park SJ, Wang Q, Kim Y, Min W. Tumor necrosis factor alpha-induced desumoylation and cytoplasmic translocation of homeodomain-interacting protein kinase 1 are critical for apoptosis signalregulating kinase 1-JNK/p38 activation. J Biol Chem. 2005;280(15):15061-70.

59. Cancer Cell Line Encyclopedia. https://portals.broadinstitute.org/ccle/. Accessed 30 Nov 2018.

60. Pearson G, Robinson F, Beers Gibson T, Xu BE, Karandikar M, Berman K, Cobb MH. Mitogen-activated protein (MAP) kinase pathways: regulation and physiological functions. Endocr Rev. 2001;22(2):153-83.

61. Pinal N, Martin M, Medina I, Morata G. Short-term activation of the Jun Nterminal kinase pathway in apoptosis-deficient cells of Drosophila induces tumorigenesis. Nat Commun. 2018;9(1):1541.

Ready to submit your research? Choose BMC and benefit from:

- fast, convenient online submission

- thorough peer review by experienced researchers in your field

- rapid publication on acceptance

- support for research data, including large and complex data types

- gold Open Access which fosters wider collaboration and increased citations

- maximum visibility for your research: over $100 \mathrm{M}$ website views per year

At $\mathrm{BMC}$, research is always in progress.

Learn more biomedcentral.com/submissions 